Short report

\title{
Physical abuse against elderly persons in institutional settings
}

\author{
Sofia Lalanda Frazão a, b, c, d, *, 1 , Ana Margarida Correia ${ }^{\text {a, } 1}$, Pedro Norton ${ }^{\text {e, }}$ \\ Teresa Magalhães ${ }^{a, b, c, ~ d ~}$ \\ ${ }^{a}$ Department of Legal Medicine and Forensic Sciences, Faculty of Medicine of Porto University, Portugal \\ ${ }^{\mathrm{b}}$ North Branch of the National Institute of Legal Medicine and Forensic Sciences, Porto, Portugal \\ ${ }^{c}$ Abel Salazar Biomedical Science Institute, Porto, Portugal \\ d Forensic Science Center - CENCIFOR, Coimbra, Portugal \\ e Institute of Public Health, Faculty of Medicine of Porto University, Portugal
}

\section{A R T I C L E I N F O}

\section{Article history:}

Received 12 June 2015

Received in revised form

16 August 2015

Accepted 3 September 2015

Available online 11 September 2015

\section{Keywords:}

Forensic medicine

Abuse

Elder

Caregiver

Institutional setting

Nursing home

\begin{abstract}
A B S T R A C T
Introduction: People over 65 years old are expected to be an increasing group exposed to abuse. Despite the well-studied intra-familial abuse, institutional abuse still lacks a proper understanding about its determinants and characteristics.

Aim: The general objective of this study is to provide a better knowledge about physical abuse against elderly people in institutional settings, in order to contribute to a timely detection, correct forensic diagnosis and prevention of these cases.

Methods: A retrospective study was conducted through the analysis of forensic medical exams performed in the North Forensic Medical Services of Portugal, between 2004 and 2013, to elderly persons allegedly victims of physical abuse in an institutional setting by a caregiver $(\mathrm{n}=59)$.

Results: All the alleged cases occurred in nursing homes and in most of them (93.2\%) the charges were against the institution and not focussing on a particular individual. The alleged victims were mainly female (79.7\%), 75 years or older (75.9\%), presenting a severe disability (55.9\%) and $47.2 \%$ being unable to communicate. No injuries or post-traumatic pain were found in $55.9 \%$ of the cases to support the charge of physical abuse. Only in $6.8 \%$ of the cases were the forensic medical findings suggestive of physical abuse and, although this was not the object of the examination, $69.1 \%$ were considered suggestive or highly suggestive of neglect. A statistically significant association was found between the alleged victim's degree of disability and the occurrence of neglect $(p=0.003)$.

Conclusion: The sample's size seems to be underestimated, probably due to lack of detection and/or reporting. The condition of these persons, mainly related with their inability to perceive abusive behaviours and/or to disclose them (mostly by physical and/or mental disability), as well as their reluctance to press charges due to fear of reprisal, affects significantly the detection and diagnosis of physical abuse, particularly in whom injuries are not obvious. In anticipation to the rapid ageing of the population, it is urgent to analyse and understand this emerging issue so that social policies and regulation may be developed, in an effort to protect the elderly, as well as to make improvements in the professionals' skills. ๑) 2015 Elsevier Ltd and Faculty of Forensic and Legal Medicine. All rights reserved.
\end{abstract}

\section{Introduction}

According to the World Health Organization (WHO), elder maltreatment is defined as "a single or repeated act or lack of appropriate action, occurring within any relationship in which

* Corresponding author. Faculty of Medicine of Porto University, Alameda Prof. Hernâni Monteiro, 4200-319 Porto, Portugal. Tel.: +351 938464859.

E-mail address: lalanda77@hotmail.com (S.L. Frazão).

1 These authors contributed equally to this work. there is an expectation of trust, that causes harm or distress to older people". Elder maltreatment comprises neglect, financial exploitation, mental abuse, psychological/emotional abuse and physical abuse. ${ }^{2}$ Physical abuse consists of "wilful infliction of physical pain or injury, including hitting, striking, pinching, slapping, shaking, pushing, grabbing, handling in a rough manner, or injuring someone in another way". ${ }^{3}$ Physical coercion and sexual abuse are also included as a subset of physical abuse. ${ }^{2}$

With the progressive increase in life expectancy, people over 65 years are estimated to represent $25 \%$ of the European population by 
2050, against the $14 \%$ in 2010 . $^{1}$ The same trend may be observed in Portugal, where, in 2011, the elderly represented $19 \%$ of the population, ${ }^{4}$ with $3.9 \%$ of these being in institutional care. ${ }^{1}$ Also, the Portuguese National Institute of Statistics foresees that there will be 307 elders for each 100 young people under 18 in 2060, as opposed to the ratio of $131: 100$ seen in $2012 .^{5}$

Following this is the arising of the "oldest old", people older than 85 years old, more susceptible to chronic and disabling diseases, cognitive impairment and even more dependent with greater needs of long-term care. ${ }^{2,6,7}$ As a result, the families of these elders require institutional care more often, which can lead to an overload of the professional caregivers, increasing their risk of burnout and, subsequently, placing the elders at higher risk of abuse. ${ }^{2,6,8-10}$

In the WHO European Region, it is estimated that physical abuse against people aged 60 years and older affects at least 4 million every year, a prevalence of $2.7 \%$ which is expected to increase, as this population continues to grow, accentuating the stress on family and professional caregivers. ${ }^{2}$ On top of that, the ongoing economic crisis inflates the strain on the caregivers, also facilitating the occurrence of abuse. ${ }^{2,9}$

Abuse affects psychological, mental and physical well-being, contributing to decrease quality of life, increase morbidity (including functional and cognitive impairment), mortality and health costs. ${ }^{2,10,11}$ These consequences create a vicious cycle of more dependency and deterioration of health, more need for longterm care, more caregivers' burnout, hence more violence towards the elderly. ${ }^{1}$

Despite the well-studied familial abuse, institutional abuse still lacks proper analysis of its risk factors, with low detection and reporting rates. ${ }^{2,6,7,11,12}$ Therefore, and in anticipation to the expected increased prevalence following the rapid ageing of the population, it is urgent to analyse and understand this emerging issue so that social policies and regulation may be developed, in an effort to protect the elderly, as well as to make improvements in professionals' training. ${ }^{13}$

The general objective of this study is to provide a better knowledge about physical abuse against elderly persons in institutional settings, in order to contribute to a timely detection, correct forensic diagnosis and prevention of these cases. Specific aims are: (a) to determine the number of cases reported to the North Forensic Medical Services of Portugal in a ten years period; (b) to characterise the alleged victims and abusers; (c) to characterise the alleged abuse, regarding its mechanism, resultant injuries and consequences.

\section{Methods}

A retrospective study was conducted using forensic medical reports (FMR) selected accordingly to the following inclusion criteria $(n=59)$ : (a) alleged victim of physical abuse in an institutional setting by a caregiver; (b) 65 years or older; (c) submitted to a forensic medical evaluation (FME); (d) at the North Services of the National Institute of Legal Medicine and Forensic Sciences of Portugal; (e) between 2004 and 2013.

From each FMR, data was collected on: (a) the alleged victims' and abusers' socio-demographic characteristics; (b) the alleged abuse's (previous and current) characteristics; and (c) the FME findings.

Age was categorised into two values ([65; 75 years [ and $\geq 75$ years) according to previous evidence (from WHO Europe) stating this cut point as a risk factor for elder abuse ${ }^{1}$; concerning the same variable, 74 years old corresponded to the 25th percentile of the sample. Degree of disability was coded into two categories: mild/ moderate and severe, the latter defined by a third person dependency with loss of autonomy for daily living activities.

Results were statistically analysed using SPSS (Statistical Package for Social Science - SPPS INC, Chicago, Illinois, USA) version 22.0, for Windows. Continuous variables were described using mean, median and standard deviation and represented in the form of histogram. Contingency tables were used to describe the categorical variables and Chi-Square test was performed to compare those variables, applying Fisher's correction when necessary. The significance level adopted was $p<0.05$.

\section{Results}

A total of 1479 FME was found due to suspicion of elder abuse: $4 \%(n=59)$ occurred in an institutional setting while the remaining were related to intra-familial abuse.

\subsection{Alleged victims' and abusers' socio-demographic characterisation}

Most alleged victims were female ( $n=47,79.7 \%), 75$ years or older ( $n=41,75.9 \%$ ), with a mean age of 79.7 (Min $=66$, Max $=107)$, all retired and mostly without a partner $(51.5 \%$ widowed or divorced and $39.4 \%$ single). The majority presented some degree of disability: mild/moderate $(n=22,37.3 \%)$ or severe ( $n=33,55.9 \%)$. Twenty-six victims $(47.2 \%)$ were unable to communicate and 1 (1.8\%) experienced difficulties in doing so, just being able to answer simple questions. Multiple disabilities were the most frequent (54.5\%), followed by motor disability (21.8\%), as shown on Table 1; within the first, an association of mental and motor disabilities was mainly found ( $n=25,83.3 \%$ ). There was no information on the alleged victims' degree of education neither on previous familial history of abuse. As the distribution of the duration of stay in the nursing home was asymmetrical, the median was used to measure this variable and equalled to 17 months (Min = 3 days, Max = 147 months). Most of the alleged victims were in the nursing home for a year or less ( $n=17,45.9 \%$ ).

Only in 4 FMR an alleged abuser was identified. In the remaining cases $(n=55,93.2 \%)$ the complaints were against the nursing home and not focussing on a particular individual (corresponding to 10 nursing homes). From the identified alleged abusers, 2 were male employees in the nursing home and the other 2 , both females, were the owners of the nursing home ( 1 with previous charges of offense to the physical integrity and maltreatment). No information on abusers' age, education, substance consumption, psychiatric disorders or previous familial history of abuse was available.

\subsection{Alleged abuse characterisation}

In most FMR ( $n=55,93.2 \%$ ) previous episodes of alleged abuse (either occurring in the same nursing home or perpetrated by the same alleged abuser) were not described. Only 2 alleged victims denied the existence of such episodes, whereas 2 other living in the same nursing home mentioned previous abuse, both by the same institutional caregiver - a female employee currently not working in that institution. In 1 of these, psychological abuse (threat of physical aggression and death threat) and physical abuse (with a belt), associated with hygiene neglect were described. The other alleged victim referred psychological abuse (threat of physical aggression and death threat) associated with physical abuse (grasping), having pressed charges to the police. The frequency and duration of abuse, as well as its consequences, were unknown in both cases.

Regarding the current alleged physical abuse, all the cases occurred in nursing homes, with none reported in day centres or 
Table 1

Alleged victim's disability characterisation.

\begin{tabular}{|c|c|c|}
\hline & \multicolumn{2}{|l|}{ Type of disability } \\
\hline $\begin{array}{l}\text { Mental } \\
\qquad(n=11,20 \%)\end{array}$ & \multicolumn{2}{|c|}{$\begin{array}{l}\text { NSD }(n=4) \text {; NSD with inability to communicate }(n=3) \text {; NSD with inability to communicate and epilepsy }(n=1) \text {; } \\
\text { Mixed aphasia with ITC }(n=1) \text {; Schizophrenia and difficulty in communication }(n=1)\end{array}$} \\
\hline $\begin{array}{l}\text { Motor } \\
\qquad(n=12,21.8 \%)\end{array}$ & \multicolumn{2}{|c|}{$\begin{array}{l}\text { Paraparesis }(n=4) \text {; Monoparesis }(n=2) \text {; Loss of sphincter continence }(n=1) \text {; Hemiparesis and NSOAP }(n=1) \text {; Hemiparesis, NSOAP } \\
\text { and loss of sphincter continence }(n=1) \text {; Paraparesis and loss of sphincter continence }(n=1) \text {; Tetraparesis, loss of sphincter } \\
\text { continence and dysarthria with ITC }(n=1) \text {; Triplegia and loss of sphincter continence }(n=1)\end{array}$} \\
\hline $\begin{array}{l}\text { Sensorial } \\
\qquad(n=2,3.6 \%)\end{array}$ & \multicolumn{2}{|c|}{ Unilateral decreased visual acuity $(n=1)$; Deaf-mute $(n=1)$} \\
\hline \multirow[t]{5}{*}{$\begin{array}{l}\text { Multiple } \\
\qquad(n=30,54.5 \%)\end{array}$} & $\begin{array}{l}\text { Mental and Motor } \\
(n=25,83.3 \%)\end{array}$ & $\begin{array}{l}\text { Alzheimer's disease with ITC, NSOAP, tetraparesis }(n=2) \text {; Alzheimer's disease with ITC, tetraparesis and loss } \\
\text { of sphincter continence }(n=2) \text {; Alzheimer's disease with ITC and apraxia }(n=1) \text {; Alzheimer's disease with ITC } \\
\text { and loss of sphincter continence }(n=1) \text {; Aphasia with ITC and hemiparesis }(n=1) \text {; Aphasia with ITC, hemiparesis } \\
\text { and loss of sphincter continence }(n=1) \text {; Aphasia and tetraparesis }(n=1) \text {; NSPP with ITC, tetraparesis and loss of } \\
\text { sphincter continence }(n=1) \text {; NSD and hemiparesis }(n=1) \text {; NSD and paraparesis }(n=1) \text {; NSD and tetraparesis } \\
(n=1) \text {; NSD with ITC, NSOAP and tetraparesis }(n=2) \text {; NSD with ITC and loss of sphincter continence }(n=1) \text {; } \\
\text { NSD with ITC and paraparesis }(n=1) \text {; NSD with ITC and tetraparesis }(n=1) \text {; NSD with ITC, epilepsy, } \\
\text { tetraparesis and loss of sphincter continence } \\
(n=1) \text {; NSD with ITC, hemiparesis and loss of sphincter continence }(n=1) \text {; NSD, depression and tetraparesis } \\
(n=1) \text {; NSD, depression, hemiparesis and dysarthria }(n=1) \text {; NSD, epilepsy, tetraparesis and loss of } \\
\text { sphincter continence }(n=1) \text {; Parkinson's disease with dementia }(n=1)\end{array}$ \\
\hline & $\begin{array}{l}\text { Mental and Sensorial } \\
(n=2,6.7 \%)\end{array}$ & NSD and bilateral decreased hearing acuity $(n=1)$; NSPP and decreased visual acuity $(n=1)$ \\
\hline & $\begin{array}{l}\text { Motor and Sensorial } \\
(n=1,3.3 \%)\end{array}$ & NSD, anxiety disorder and albinism $(n=1)$ \\
\hline & $\begin{array}{l}\text { Mental and Other } \\
(n=1,3.3 \%)\end{array}$ & NSD and muteness $(n=1)$ \\
\hline & $\begin{array}{l}\text { Mental, Motor and } \\
\text { Sensorial }(n=1,3.3 \%)\end{array}$ & NSPP with ITC, NSOAP, blindness, deafness $(n=1)$ \\
\hline
\end{tabular}

ITC = Inability to communicate; NSD = Non-specified dementia; NSOAP = Non-specified osteoarticular pathology; NSPP = Non-specified psychiatric pathology.

home care settings. In the majority of the suspected cases in which this information was available $(n=29)$, the report to the authorities was made by the Social Security Office ( $n=17,58.6 \%)$, often associated with the nursing home's lack of proper licensing; anonymous report represented $24.1 \%(n=7)$ and familial report $6.8 \%$ $(n=4)$; the victim reported in only $13.8 \%(n=1)$. Allegation of physical abuse appeared isolated in $93.2 \%$ of the cases $(n=55)$ and associated with neglect in $3.4 \%(n=3)$. The main recognised mechanism of aggression was grasping $(n=10,83.3 \%)$ and, in 2 cases, multiple mechanisms were mentioned (pushing and punching; slapping and aggression with a scissors), although in most cases this information was unknown $(n=47)$, due to communication limitations during the FME. Only 4 alleged victims were taken by family members $(n=3)$ or an employee of the nursing home $(n=1)$ to seek for medical care due to suspicion of abuse, being then relocated to another nursing home or to a relative's home.

\subsection{Forensic medical findings}

No injuries or post-traumatic pain were found in $55.9 \%$ of the cases $(n=33)$; in the remaining, the resulting injuries were abrasions ( $n=4,6.8 \%$ ), bruises ( $n=12,20.3 \%$ ) and multiple superficial injuries in the skin ( $n=10,16.9 \%)$. Within the 26 cases presenting injuries, $42.3 \%$ were in multiple locations $(n=11)$, followed by injuries located only on the upper limbs $(n=8,30.8 \%)$, as displayed on Table 2. Injuries demanded a maximum of 9 days to heal. There were only 2 cases (8.3\%) in which the patients presented permanent consequences (scars) allegedly associated with the abuse in analysis. The FME concluded that the findings were non-specific of physical abuse in $93.2 \%$ of the cases and just in $6.8 \%(n=4)$ were they considered as suggestive. During the FME, 9 cases $(15.3 \%)$ of decubiti sores were noticed. This finding, associated with victims' complaints and other medical observations, lead forensic physicians to conclude that $52.7 \%$ of the cases $(n=29)$ were highly suggestive of neglect and $16.4 \%(n=9)$ were suggestive of neglect; among these, medication and medical care neglect appeared as the main finding ( $n=32,84.2 \%$ ), followed by medical care neglect $(n=6,15.8 \%)$.

As described on Table 3, in alleged cases of physical abuse there was no significant relation between the conclusion of the FME and the alleged victim's characteristics, specifically sex, age, degree of disability or type of disability. Likewise, no significant relation existed between the occurrence of neglect and the alleged victim's sex, age or type of disability. Nevertheless, a statistically significant association was found between the alleged victim's degree of disability and the occurrence of neglect.

\section{Discussion}

This is the first Portuguese study on this subject, concerning a forensic medical sample. FME in cases of suspected abuse, including of elderly people, are mandatory in Portugal and are always performed by examiners of the National Institute of Legal Medicine and Forensic Sciences. Considering we analysed FMR during a ten years period, this $4 \%$ of the total FME performed due to suspicion of elder abuse seems to be an underestimation of the reality, probably due to underreport. Also, the FME due to institutional abuse was

Table 2

Location of the resulting injuries.

\begin{tabular}{lcl}
\hline & $n(\%)$ & Location of injury $(n)$ \\
\hline Face & $2(7.7)$ & \\
Torso & $3(11.5)$ & \\
Upper limbs & $8(30.8)$ & \\
Lower limbs & $2(7.7)$ & \\
Multiple & $11(42.3)$ & Head and upper limbs $(n=1)$ \\
& & Head, face and upper limbs $(n=2)$ \\
& Torso and upper limbs $(n=1)$ \\
& Torso and lower limbs $(n=1)$ \\
& Torso, upper and lower limbs $(n=1)$ \\
& Upper and lower limbs $(n=5)$ \\
\hline
\end{tabular}


Table 3

Compatibility between the forensic medical findings and the complaint according to the alleged victim's characteristics.

\begin{tabular}{|c|c|c|c|c|c|c|c|c|}
\hline & & \multicolumn{3}{|l|}{ Physical abuse } & \multicolumn{4}{|l|}{ Neglect } \\
\hline & & $\begin{array}{l}\text { Suggestive of } \\
\text { physical abuse } n(\%)\end{array}$ & $\begin{array}{l}\text { Non-specific of } \\
\text { physical abuse } n(\%)\end{array}$ & $p$ & $\begin{array}{l}\text { Non-specific of } \\
\text { neglect } n(\%)\end{array}$ & $\begin{array}{l}\text { Suggestive of } \\
\text { neglect } n(\%)\end{array}$ & $\begin{array}{l}\text { Highly suggestive } \\
\text { of neglect } n(\%)\end{array}$ & $p$ \\
\hline \multirow[t]{2}{*}{ Sex } & Male & $2(16.7)$ & $10(83.3)$ & 0.127 & $5(41.7)$ & $3(25)$ & $4(33.3)$ & 0.394 \\
\hline & Female & $2(4.3)$ & 45 (95.7) & & $16(34)$ & $6(12.8)$ & $25(53.2)$ & \\
\hline \multirow[t]{2}{*}{ Age } & [65;75 years] & $1(7.7)$ & $12(92.3)$ & 0.964 & $7(53.8)$ & $3(23.1)$ & $3(23.1)$ & 0.205 \\
\hline & $\geq 75$ years & $3(7.3)$ & $38(92.7)$ & & $14(34.1)$ & $6(14.6)$ & $21(51.2)$ & \\
\hline \multirow{3}{*}{$\begin{array}{l}\text { Degree of } \\
\text { disability }\end{array}$} & None & $1(25)$ & $3(75)$ & 0.316 & $1(25)$ & $2(50)$ & $1(25)$ & 0.003 \\
\hline & Mild/Moderate & $1(4.5)$ & $21(95.5)$ & & $14(63.6)$ & $2(9.1)$ & $6(27.3)$ & \\
\hline & Severe & $2(6.1)$ & 31 (93.9) & & $6(18.2)$ & $5(15.2)$ & $22(66.7)$ & \\
\hline \multirow{4}{*}{$\begin{array}{l}\text { Type of } \\
\text { disability }\end{array}$} & Mental & $1(9.1)$ & 10 (90.9) & 0.837 & $5(45.5)$ & $2(18.2)$ & $4(36.4)$ & 0.865 \\
\hline & Motor & $1(8.3)$ & 11 (91.7) & & $3(25)$ & $1(8.3)$ & $8(66.7)$ & \\
\hline & Sensorial & 0 & $2(100)$ & & $1(50)$ & 0 & $1(50)$ & \\
\hline & Multiple & $1(3.3)$ & 29 (96.7) & & $11(36.7)$ & $4(13.3)$ & $15(50)$ & \\
\hline
\end{tabular}

frequently demanded to the forensic medical services not referring to an individual but to a nursing home (93.2\%, corresponding to 10 nursing homes), which may include several alleged victims. Furthermore, as noticed in the results, the main motivation for the report was not the suspicion of physical abuse by itself, but administrative or legal issues, namely related to the lack of proper licensing (58.6\%).

It was not possible to use our data to estimate the prevalence of institutional elder abuse in the Portuguese northern area, since there are no available numbers by region of elders living in institutional settings. Difficulties in estimating prevalence and incidence of institutional elder abuse is referred in various studies, $6,14,15$ with underreport being the justification found for this fact. ${ }^{1,2,16}$

Possible explanations for underreport have been proposed, such as elderly feeling of shame and fear of retaliation after disclosing the abuse to the authorities, $6,14,17,18$ lack of elderly knowledge on how to do $\mathrm{it}^{6}$ or their inability to communicate, due to mental disability or other, ${ }^{6,18}$ this corresponding to $47.2 \%$ of our sample. Another explanation would be fear of reprisal and criminal consequences experienced by nursing homes' staff when admitting an abusive behaviour or denunciating one perpetrated by their co-workers. ${ }^{6}$ At this level, it might be pertinent to ensure the existence of policies that guarantee staff's and elder's protection in case of report. Lack of available information to the population and specific training for professionals, resulting in uncertainty on defining criteria, low index of suspicion and/or divergent tolerance levels regarding what constitutes elder abuse, might also explain the difficulty in recognising and reporting possible abusive situations. ${ }^{1,14-16,18}$ In fact, difficulty in discerning what is a risk factor, sign or symptom of abuse from predictable outcomes of the elder's disability also plays an important role on underreporting.,16 Therefore, investing in staff education and developing protocols to evaluate elders at risk, as well as to provide accurate information to the residents and their families regarding their rights, the identification of risk factors and on how to proceed in order to report potential cases of abuse, might prove to be important to reverse the current tendency. ${ }^{6,15,16} \mathrm{~A}$ benefit of earlier detection of abuse, as well as neglect, is the prevention of its evolution and, consequently, of worse outcomes or escalation of violence, leading to greater treatment-related costs for the society. ${ }^{14}$ O'Brien also advocates that physicians' reluctance in getting involved with Adult Protective Services may explain the lower reporting rates in this professional category. ${ }^{14}$ Although Adult Protective Services do not exist in Portugal as a separate entity, this reluctance might also occur regarding an involvement with the judicial system, as in our sample there were no cases reported by health care professionals.

\subsection{Alleged victims', abusers' and risk factors}

According to the literature, victims of elder abuse in general (in familial and extra-familial contexts) are women in $62 \%$ of the cases. ${ }^{2,14}$ A similar tendency was found in European statistics on maltreatment in nursing homes ${ }^{1}$ and in our study, with female representing $79.7 \%$ of the alleged victims. Nevertheless, further research would be recommended in order to understand if sex should be considered as a risk factor for institutional abuse, since there are only a few studies on the matter and one of them establishing a higher percentage of male victims (56.7\%). ${ }^{19}$ Regarding alleged victim's age, $75.9 \%$ of our subjects were 75 years or older, a predisposition in harmony with European evidence that elder maltreatment rises after this age, ${ }^{1}$ but no data was found concerning such relation in institutional abuse. Another recognised risk factor and a potential silencer for elders in institutional settings in Europe is their social isolation, due to absence of family members or regular visitors, ${ }^{1}$ an aspect not assessed in our sample since there was no available information regarding this item in the FMR. Concerning the victim's disability, $49 \%$ were unable or experienced difficulties in communicating. This is a higher percentage than the one reported in the 2011 National Portuguese Census, in which 10\% of Portuguese elders had daily difficulties in understanding others and making themselves understood. ${ }^{4}$ The latter experienced additional difficulties in daily living activities, such as walking (27\%), bathing and dressing (14\%), seeing (19\%), earing (15\%), memory and concentration (15\%), ${ }^{4}$ consistent with our sample's more frequent disabilities: multiple (54.5\%, with the majority corresponding to an association of mental and motor disability), motor (21.8\%) and mental (20\%), as displayed on Table 1.

Another known risk factor for abuse described in other studies is the scarce number of staff to attend the residents' needs, leading to excessive workload, stressful work environment and professionals' burnout. ${ }^{1,2,15}$ In our sample, in spite of not having information on the number of employees, $30.5 \%$ of the FMR suggested insufficient staff's training or experience in patient's handling techniques, which can justify the observed injuries, a finding corroborated by other authors. $^{1,6,15}$ In most situations (93.2\%), the charges were against the nursing home, so it was impossible to identify and describe most of the alleged abusers, hence the inability to draw conclusions in accordance to other studies, for instance, to find a connection between elder abuse and the abuser's personality traits, taking in consideration intergenerational transmission of violence. $^{1,6}$

Due to the interaction among factors of the individual, relationship, community and societal levels, the ecological model is useful for considering risks and understanding the types of 
programmes that need to be implemented at different levels. ${ }^{1}$ Schiamberg et al. (2011), proposed an ecological framework for institutional elder abuse that covers the study of the dynamic relationship of the coparticipants in context, which is divided into multiple levels: (a) the study of the microsystem, that includes the characteristics of the nursing home (location, size or physical design) and the impact of broad institutional design on the older adult-caregiver dyad; (b) the mesosystem, which is the cumulative impact of at least two microsystems on the likelihood of abuse; (c) the exosystem, that comprises the relationship between at least two microsystems, one of which does not contain either the older adult or the institutionalised caregiver; (d) the macrosystem, or the interaction between the welfare of the older adult nursing home resident and the broad social values and related stereotypes of the ageing process and ageing individuals; (e) and the chronosystem, or the impact of time on the multiple levels or contexts of potential abuse. $^{2}$

However, due to the nature of our study (a retrospective analysis of FMR with a small sample size enclosing little information on the risk factors for elder maltreatment), it was only possible to do an individual level of analysis of the risk factors described in the FMR (independent microsystems). This is an important limitation of our study, since it can produce an interpretation bias, namely viewing the results individually and ignoring the interaction between multiple risk factors. Nonetheless, the results obtained provide relevant knowledge concerning the FME and the FMR in how to elaborate future strategies in order to gather the necessary information to do a comprehensive research when doing this type of medical evaluation. The results also raise some issues concerning the health care professionals' education, which can be solved by providing specific formation on this matter (including risk factors identification, the ecological model framework and injuries interpretation), thus contributing to a timely detection, an accurate forensic medical diagnosis and prevention.

\subsection{Alleged abuse and forensic medical findings}

An absence of resulting injuries or post-traumatic pain to support the suspicion of physical abuse was verified in $55.9 \%$ of the cases. This may be explained by the fact that when a charge is pressed against a given institution, the FME is not performed immediately. Legal constraints such as gathering a team composed by forensic physicians, public prosecutor and police, among others, determine a variable delay in the FME. During this period, alleged evidence might be destroyed or lost with the healing of the alleged injuries. In our study, the referred multidisciplinary intervention was only verified in the major metropolitan areas and when requested by the Public Prosecutor's Office. Even in these cases, it was not always possible to examine and elaborate the respective FMR of every elder attending that nursing home, because of the high occupancy rates, so the criteria of choice diverged: either applying a random selection or examining patients with suggestive signs of abuse or the ability to communicate were set as eligible criteria. For instance, from a complaint concerning a nursing home with 130 patients, only 7 FMR were elaborated and the remaining patients were submitted to a brief interview and medical examination.

The resulting injuries verified in our sample were present in multiple locations in $42.3 \%$, followed by the upper limbs (30.8\%), as described on Table 2, a different finding from a literature review in which the distribution of injuries was upper limbs (43.98\%), maxillofacial and neck (22.88\%), skull and brain (12.28\%), lower limbs $(10.61 \%)$ and torso $(10.25 \%){ }^{20}$ This difference might be explained due to the review's focus not being institutional abuse and also to the exclusion of multiple locations for the statistical analysis.

In the USA, in a study that reviewed over than 20000 reports of abuse and neglect, physical abuse was the most frequently found ${ }^{14}$ and, in Arizona, 63.6\% of physical abuse complaints were substantiated. $^{3}$ However, in our study only $6.8 \%$ of the forensic medical findings were suggestive of physical abuse, according to the following criteria: (a) the explanation provided did not suit the injury's characteristics; injuries located in typical non-accidental areas; (b) patterned injuries; (c) injuries in different stages of healing; (d) delay between injury production and seeking for health care. It is important to emphasize that even with these criteria, the differential diagnosis between intentionally inflicted injuries, accidental injuries, self-inflicted injuries and pathological or age related lesions is particularly difficult. This underlines the importance of forensic physicians, especially experienced in this diagnosis and the FMR use for this kind of evaluations. On the other hand, we found $69.1 \%$ of the forensic medical findings to be highly suggestive or suggestive of neglect, as opposed to an initial suspicion of $93.2 \%$ of isolated physical abuse and $3.4 \%$ of physical abuse associated with neglect motivating the FME. Neglect is "the refusal or failure to fulfil caretaking obligations and to meet the needs of the elder in order to punish or harm him/her, including behaviour such as deliberate abandonment or denial of food, medication, and health services" ${ }^{2}$ and when it happens in institutional settings, proof has been found that it usually derives from institutional problems. ${ }^{15}$ According to the European Report on preventing elder maltreatment, the existence of dependence, any kind of physical or mental disability or cognitive impairment appear as a risk factor for maltreatment in institutional settings. ${ }^{1}$ Nevertheless, in our sample no significant relation was found between the diagnosis of physical abuse and the alleged victim's degree of disability or type of disability, as shown on Table 3. This was also documented by Schiamberg et al. (2012), stating that "older adults with a simple diagnosis of Alzheimer's disease or a diagnosis of cognitive impairment (e.g. failing memory, difficulty communicating, or difficulty concentrating) were not found to be at higher risk of physical abuse than patients without such diagnoses" ${ }^{13}$ Schiamberg et al. (2011) also states that "poor health and functional impairment predict neglect but not physical abuse". ${ }^{2}$ Similarly, in our study a statistically significant association was found between the alleged victim's degree of disability and occurrence of neglect $(p=0.003)$. This corroborates our deduction that the greater the degree of disability, the greater will be the predisposition to neglect. There can be some explanations for these findings. Firstly and regarding physical abuse, the delay between the report of an alleged physical abuse and the FME, justifies the loss of physical evidence and therefore prevents the confirmation of the alleged abuse. On the other hand, and in what concerns the occurrence of neglect, this delay is not as important as for the physical abuse, due to being almost impossible to hide some of the evidence that suggests neglect, such as the existence of decubiti sores with inadequate treatment, the absence of the medical and medication charts on the elder medical file, the negative results of toxicological exams in highly dependent elders (who were supposed to be on daily medication and with daily medical needs) and even their overall appearance during the FME (e.g., clothing, personal hygiene).

\subsection{Limitations and suggestions}

A major limitation concerns the short number of cases composing our sample $(n=59)$, reflecting the low reporting rates in the Portuguese northern region and, consequently, contributing to the underestimation of the institutional abuse's real prevalence. Also, with data being retrieved from a limited region 
of Portugal, results may not be extrapolated to the general population, a common setback in several studies, ${ }^{16}$ as well as small sample sizes. ${ }^{6}$

Other limitation is the amount of missing data in the FMR concerning the alleged victims, their personal and family background, the alleged abusers and their personal background, the interaction between them, the institution and the society (for example, aspects like feeding, personal hygiene, clothing, medication and medical care, family interaction, recreation, the alleged victim's relationship with the caregiver and the institution, and the family relationship with the caregiver and the institution, the description of the victim's degree of disability and the staff's working conditions). One of the possible explanations for this lack of information can be the elders' difficulty in communicating (due to mental and sensorial disability, such as confusion, dementia, aphasia, dysarthria or muteness) or the absence of a multidisciplinary approach in the elaboration of the FMR.

It is clear that the obtained results do not fully answer the proposed objectives, due to the previously discussed limitations about the FMR. However, they highlight the importance of the FMR in improving the knowledge on elder maltreatment in institutional settings and the need to apply multiple changes to the current model of FMR, namely in a multidisciplinary approach.

Despite the extensive study already done in domestic violence, little attention has been given or progress has been made regarding elder institutional abuse and neglect. This by itself presents as an opportunity and idea for future studies, namely in Portugal, but also as a major limitation, since little scientific information exists on the matter. Its real prevalence, risk factors, best approach or outcomes, for instance, are still uncertain., ${ }^{1,6,14}$ However, it also comes as a challenge and a necessity to use the present knowledge to raise public awareness in hopes of inflating identification, report rates and actions to prevent elder maltreatment. ${ }^{17}$ Health care professionals play an essential role in detection of possible abusive scenarios, so their training should be seen as a necessity and good investment. Cooper et al. also suggested the establishment of caregivers' education on mental illnesses, such as dementia, team work and management of challenging behaviours, as a preventive strategy at potential abuser's level. ${ }^{18}$

Understanding why institutional abuse occurs might prove to be more important than making out its prevalence, in order to elaborate preventive strategies. ${ }^{6}$ So, it is important to study the characteristics of the nursing homes, in a way to potentially promote modifications to the legislation and proposals on educational programs attended by institutional caregivers. For example, the nursing home's tolerance level of abuse, if there are nonflexible routines and regimes, excessive programming or lack of socio cultural activities, the adequacy of the staff:patient rate and its employees' degree of education. Investigating protective factors of elder abuse in institutional settings also comes as an interesting approach, already suggested as may including enabling elders' independence and the existence of an emotionally supportive familial system. ${ }^{2}$ Finally, it might be useful to create pre-determined forms for FME of alleged cases of institutional abuse.

\section{Conclusion}

From this study, we can conclude:

1. The sample's size (in a 10 years period) representing $4 \%$ of the FME due to suspicion of elder abuse seems to be an underestimation of the reality, probably due to underreport;

2. The alleged victims were mostly female ( $80 \%), 75$ years or older (76\%);
3. The majority presented a severe disability (56\%), additionally $49 \%$ were unable or experienced difficulties in communicating, which might explain the low reporting rates and why, when a complaint is made, it is usually anonymous or comes from a family member or the Social Security Office;

4. All the cases of alleged abuse occurred in nursing homes;

5. In most cases (93\%) the complaints were against the nursing home and not focussing on a particular individual;

6. No injuries or post-traumatic pain were found in $56 \%$ of the cases, to support the charges of physical abuse, a fact that may be explained by the legal constraints, determining a variable period of time between the presentation of complaint and the FME;

7. Only in $7 \%$ of the FMR were the forensic medical findings suggestive of physical abuse, 53\% were considered as highly suggestive of neglect and $16 \%$ as suggestive of neglect, with the medication and medical care neglect appearing as the main finding ( $84 \%)$, followed by medical care neglect (16\%);

8. A statistically significant association was found between the alleged victim's degree of disability and the occurrence of neglect.

Understanding why institutional abuse and neglect occur might prove to be more important than making out their prevalence, in order to elaborate preventive strategies and promote a timely detection and diagnosis of these cases. For that purpose, the analysis of FMR seems to be relevant. However, we noticed that the FMR information is limited and does not allow us to answer a certain number of fundamental topics. Regarding this, it is necessary to develop a proposal of a new model of FMR, considering a multidisciplinary intervention. These reports should include, for example, the description of the known risk factors, according to an ecological perspective adapted to institutional settings ${ }^{2}$ : (a) the victim's demographic factors/individual characteristics, health and behaviour problems, social context, including questions about feeding, personal hygiene, clothing, medication and medical care, and recreation; (b) the caregiver's personality traits/individual characteristics, health and social context; (c) the relationship between the caregiver/elder microsystem and the caregiver/professional; (d) the relationship between the caregiver/elder microsystem and the elder/family communication microsystem; (e) the characteristics of the institutional setting - location, size, physical design, the adequacy of the staff:patient rate and its employees' degree of education, work routines, regimes and socio cultural activities.

Furthermore, the importance of the health care and forensic professionals' training on prevention, detection, reporting and diagnosing of these cases is acknowledged.

\section{Conflict of interest}

There were no potential conflicts of interest with respect to the research, authorship, and/or publication of this article.

\section{Funding}

The authors received no financial support for the research or preparation of this article.

\section{Ethical approval}

This study was carried out in accordance with ethical rules. It has not been submitted to Ethical Approval since it was a retrospective review in which no invasive studies were carried out nor identification of the individuals was given. 


\section{References}

1. Sethi D, Wood S, Mitis F, Bellis M, Penhale B, Marmolejo II, et al. European report on preventing elder maltreatment. s.l. World Health Organization; 2011.

2. Schiamberg LB, Barboza GG, Oehmke J, Zhang Z, Griffore RJ, Weatherill RP, et al. Elder abuse in nursing homes: an ecological perspective. J Elder Abuse Negl Apr 2011:23(2):190-211.

3. Phillips LR, Guo G, Kim H. Elder mistreatment in U.S. residential care facilities: the scope of the problem. J Elder Abuse Negl 2013;25(1):19-39.

4. Instituto Nacional de Estatística, IP. Censos 2011 resultados definitivos Portugal. Lisboa: Instituto Nacional de Estatística, IP; 2012.

5. Instituto Nacional de Estatística, IP. Projeções de população residente 2012-2060. Lisboa: Unidade de Comunicação e Imagem do Instituto Nacional de Estatística, IP; March 2014.

6. McDonald L, Beaulieu M, Harbison J, Hirst S, Lowenstein A, Podnieks E, et al, Institutional abuse of older adults: what we know, what we need to know. J Elder Abuse Negl Apr 2012;24(2):138-60.

7. Buzgová R, Ivanová K. Elder abuse and mistreatment in residential settings. Nurs Ethics Jan 2009;16(1):110-26.

8. Phillips LR, Guo G. Mistreatment in assisted living facilities: complaints, substantiations, and risk factors. Gerontologist Jun 2011;51(3):343-53.

9. Magalhães Teresa. Violência e abuso - respostas simples para questões complexas. s.l. Imprensa da Universidade de Coimbra; March 2000. 978-989-260025-3.

10. Frazão SL, Silva MS, Norton P, Magalhães T. Domestic violence against elderly with disability. J Forensic Leg Med Nov 2014;28:19-24.
11. Cohen M. The process of validation of a three-dimensional model for the identification of abuse in older adults. Arch Gerontol Geriatr Nov-Dec 2013;57(3):243-9.

12. Burns D, Hyde P, Killett A. Wicked problems or wicked people? reconceptualising institutional abuse. Sociol Health Illn May 2013;35(4):514-28.

13. Schiamberg LB, Oehmke J, Zhang Z, Barboza GE, Griffore RJ, Von Heydrich L, et al. Physical abuse of older adults in nursing homes: a random sample survey of adults with an elderly family member in a nursing home. J Elder Abuse Negl 2012;24(1):65-83.

14. O'Brien JG. A physician's perspective: elder abuse and neglect over 25 years. J Elder Abuse Negl Jan 2010;22(1-2):94-104.

15. Natan MB, Lowenstein A. Study of factors that affect abuse of older people in nursing homes. Nurs Manag (Harrow) Dec 2010;17(8):20-4.

16. Daly J, Coffey A. Staff perceptions of elder abuse. Nurs Older People May 2010;22(4):33-7.

17. Oliveira AA, Trigueiro DR, Fernandes MG, Silva AO, Elderly maltreatment: integrative review of the literature. Rev Bras Enferm Jan-Feb 2013;66(1): $128-33$.

18. Cooper C, Dow B, Hay S, Livingston D, Livingston G. Care workers' abusive behavior to residents in care homes: a qualitative study of types of abuse, barriers, and facilitators to good care and development of an instrument for reporting of abuse anonymously. Int Psychogeriatr May 2013;25(5):733-41.

19. Payne BK, Cikovic R. An empirical examination of the characteristics, consequences, and causes of elder abuse in nursing homes. I Elder Abuse Neg1995;7(4):61-74.

20. Murphy K, Waa S, Jaffer H, Sauter A, Chan A. A literature review of findings in physical elder abuse. Can Assoc Radiol J Feb 2013;64(1):10-4. 